Minimal metastatic disease in neuroblastoma

\section{Minimal metastatic disease}

\section{M Reid}

\section{Clinical importance in neuroblastoma}

$\mathrm{T}$ he article by Burchill ${ }^{1}$ in this issue casts light on major technical advances in our ability to detect ever smaller numbers of neuroblastoma cells in the peripheral blood and bone marrow of children with this disease. But what of the question posed in its title-is this clinically important? Intuitively, the answer would seem to be "yes, at least in some children". The subject-detection of minimal quantities of tumour-and the technology are exciting; both are very "sexy". However, the protracted and significantly less "sexy" process of answering that question in a meaningful way still remains. In which children, at what stage of treatment, using what discriminating threshold of tumour cells, detected in what tissue will these approaches accurately forecast outcome? Will that forecast be significantly more accurate than can currently be achieved by conventional staging or biological features? And, finally, will intervention in specific groups of children identified by these new techniques actually improve their outcome?

\section{"It is in the design and execution of first rate clinical studies using these techniques that the real challenge still lies"}

Nearly a decade ago I asked "how far have we come?" about our ability to detect bone marrow infiltration in this disease in routine clinical practice. ${ }^{2}$ My answer was "not very far". It seems that immunological approaches (at that time a relatively "sexy" technology) have progressed only a little further. The sorts of meticulously designed studies that might have answered these questions have either not been designed or, perhaps, faltered. We certainly have not seen the publication of convincing results. To some degree, some clinicians may be relieved that they have not embarked on massive prospective studies using immunological techniques; serious doubts ${ }^{2}$ about false positive reactions using one antibody in particular,
UJ13A (anti-NCAM), have also arisen concerning the value of another potential tool, anti-GD2, which has been shown to label non-neuroblastoma cells with worrying frequency in the bone marrow of children with localised/regional disease. ${ }^{3}$ The actual number of children with apparently localised disease in whom the rather more precise combined immunological and molecular cytogenetic technique ${ }^{3}$ might reveal convincing minimal disease in the bone marrow will probably be very small. This fact only increases the difficulty in mounting really meaningful studies.

Burchill's article keeps the flame of hope alight. But there is still an awesome responsibility resting on the shoulders of practising paediatric oncologists and pathologists to ensure that the technical achievements of the scientists are not wasted. Major intellectual effort must now go into formulating questions about clinical importance and into the design of studies that might answer them. An equally determined effort must go into solving logistical problems, which might impede their execution. There can be no disguising the enormity of the task. Similar intellectual and logistical challenges have faced those trying to answer some of these sorts of questions in acute lymphoblastic leukaemia (ALL) in children. ${ }^{4}$ However, despite the much larger patient pool, the long established infrastructure for executing clinical trials in ALL in many countries, and major advances in technology, we are still anxiously awaiting formal proof that these tools really do live up to their promise, ${ }^{5}$ let alone achieve important improvements in outcome.

\section{"Perhaps, ironically, one of our handicaps has been the rapid pace of technological advance"}

So far, science has not really failed us at a technical level. True, there have been some ultimately disappointing potential tools, but perhaps these molecular tools will be better. Given the possibility that they may prove to be less plagued by non-specificity, albeit suffering from some problems in terms of accurate quantitation, it is in the design and execution of first rate clinical studies using these techniques that the real challenge still lies. In clinical research, each experiment takes a long time to deliver its results. If the design has been woolly, or flawed in its structure, or burdened by misapprehensions about what it is that we think we are measuring, it may take us years to appreciate the fact, even if the tool is in itself flawless; and few would suggest that any of the tools at our disposal are flawless.

Perhaps, ironically, one of our handicaps has been the rapid pace of technological advance. The risk remains that many clinicians and pathologists may ever remain dedicated followers of fashion, seduced by the dazzling potential of each new technological advance and slaves to serial, temporary enthusiasms, rather than becoming true (but patient) scientists. Burchill's article, ${ }^{1}$ and the potential it reveals, should stimulate us to focus our minds on how to use these molecular tools, even as we acknowledge that there may still be problems. The potential field for other similar tools is, of course, not restricted to neuroblastoma. It will be seriously disappointing if, in another 10 years' time, we find we have still not obtained definite answers to some of these questions. Even if those answers prove to be that we cannot forecast outcome accurately or, despite accurate forecasts, fail to bring about improvement in subsets of children identified by the use of these techniques, we will still be a bit further ahead than we are now.

\section{J Clin Pathol 2004:57:21}

Correspondence to: $\operatorname{Dr}$ M M Reid, Department of Haematology, Royal Victoria Infirmary, Newcastle upon Tyne, NEI 4LP, UK; Micheal.Reid@nuth.northy.nhs.úk

\section{REFERENCES}

1 Burchill SA. Micrometastases in neuroblastoma are they clinically important? J Clin Pathol 2004;57:14-20.

2 Reid MM. Detection of marrow infiltration by neuroblastoma in clinical practice: how far have we come? Eur J Cancer 1994;30A:134-5.

3 Méhes G, Luegmayr A, Ambros IM, et al. Combined automatic immunological and molecular cytogenetic analysis allows exact identification and quantification of tumor cells in the bone marrow. Clin Cancer Res 2001;7:1969-75.

4 Moppet J, Burke GAA, Steward CG, et al. The clinical relevance of detection of minimal residua disease in childhood acute lymphoblastic leukaemia. J Clin Pathol 2003;56:249-53. leukaemia. J Clin Pathol 2003;56:249
Donadieu J, Hill C. Early response to chemotherapy as a prognostic factor in childhood acute lymphoblastic leukaemia: a methodological review. Br J Haematol 2001;115:34-45. 